\title{
Analisis Unsur Inferensi Terhadap Tuturan Masyarakat Desa Megu Cilik Kabupaten Cirebon
}

\author{
Khalimi Romansyah \\ khalimiromansyah@unswagati.ac.id \\ Program Studi Pendidikan Bahasa dan Sastra Indonesia, Universitas Swadaya Gunung Jati \\ Jl. Perjuangan No.1 Kota Cirebon, Indonesia
}

\begin{abstract}
Abstrak. Tujuan penelitian ini menjelaskan tentang bentuk dan makna inferensi yang terdapat dalam tuturan masyarakat Desa Megu Cilik Kabupaten Cirebon. Obyek penelitian ini terbatas hanya pada tuturan bahasa Indonesia. Metode penelitian yang digunakan dalam penelitian ini ialah metode deskriptif kualitatif dengan pemerolehan data dari dua sumber yaitu data primer dan data sekunder. Adapun sampelnya terdiri atas sepuluh peristiwa tutur masyarakat Desa Megu Cilik Kabupaten Cirebon. Hasil penelitian menunjukkan bahwa tuturan bahasa Indonesia masyarakat Desa Megu Cilik banyak mengandung unsur inferensi. Hal ini terbukti dari sepuluh peristiwa tutur bahasa Indonesia yang diamati, semuanya mengandung unsur inferensi. Adapun bentuk dan maknanya cukup beragam.
\end{abstract}

Kata kunci: desa Megu Cilik, unsur inferensi, tuturan, masyarakat tutur

\section{Pendahuluan}

Komunikasi merupakan suatu bentuk kegiatan yang memiliki peran penting dalam kehidupan manusia karena hanya dengan komunikasi manusia bisa berinteraksi dengan sesamanya. Alat komunikasi yang utama bagi manusia adalah bahasa sebab sebagian besar kegiatan komunikasi manusia dengan sesamanya menggunakan bahasa atau kegiatan komunikasi berbahasa.

Komunikasi berbahasa memiliki kelebihan dibandingkan jenis komunikasi yang lainnya, seperti komunikasi dengan gerak isyarat tangan dan komunikasi membaca gerak bibir. Komunikasi dengan menggunakan bahasa akan tetap berjalan dalam kondisi gelap dan hal ini tidak berlaku bagi jenis komunikasi gerak isyarat tangan atau komunikasi membaca gerak bibir.

Komunikasi berbahasa akan berjalan efektif (komunikatif), bila terjadi kesepahaman antara pihak-pihak yang terlibat di dalamnya, yaitu penyapa (pembicara atau penulis) dan pesapa (pendengar atau pembaca). Hal ini akan tercapai jika pesapa mengerti atau memahami makna, baik yang tersurat maupun yang tersirat dalam tuturan yang diungkapkan oleh penyapa, artinya pesapa tidak hanya memahami makna tuturan tapi juga memahami maksud penyapa.

Salah satu upaya pesapa dalam menjalin kerja sama komunikasi dengan penyapa agar tercapai komunikasi yang efektif (komunikatif) yaitu upaya memahami makna yang secara harfiah tidak terdapat dalam tuturan yang diungkapkan oleh penyapa atau biasa disebut inferensi. Dengan demikian pesapa di samping memahami makna tuturan juga memahami maksud penyapa. Atas dasar hal itu penulis tertarik mengadakan penelitian dengan judul 
"Analisis Unsur Inferensi Terhadap Tuturan Masyarakat Desa Megu Cilik Kabupaten Cirebon."

\section{Metode}

Metode penelitian yang penulis gunakan dalam penelitian ini ialah metode deskriptif kualitatif dengan pemerolehan data dari dua sumber yaitu data primer dan data sekunder. Adapun dua sumber data tersebut akan penulis uraikan seperti di bawah ini.

1. Studi Lapangan

Dalam rangka memeroleh data primer, penulis melakukan pengamatan dan pencatatan (perekaman ) terhadap sepuluh peristiwa tutur bahasa Indonesia yang mengandung unsur inferensi dari sepuluh tempat yang berbeda di Desa Megu Cilik Kabupaten Cirebon.

2. Studi Pustaka

Untuk memeroleh data sekunder, penulis melakukan kajian pustaka dari berbagai sumber atau buku yang berhubungan dengan pokok masalah penelitian, terutama tentang inferensi beserta ragam bentuk dan maknanya.

\section{Hasil dan Pembahasan}

Hasil analisis terhadap sepuluh peristiwa tutur bahasa Indonesia masyarakat Desa Megu Cilik Kabupaten Cirebon menunjukkan bahwa semua (sepuluh) peristiwa tutur tersebut mengandung unsur inferensi. Adapun bentuk dan makna inferensinya akan penulis uraikan di bawah ini.

Dari sepuluh peristiwa tutur bahasa Indonesia masyarakat Desa Megu Cilik yang penulis analisis, terdapat tujuh peristiwa tutur yang mengandung bentuk inferensi prinsip analogi penafsiran umum dan hanya tiga peristiwa tutur yang mengandung bentuk inferensi prinsip analogi penafsiran lokal. Sementara itu makna inferensi yang terkandung dalam sepuluh peristiwa tutur tersebut meliputi : meminta bantuan pinjaman tenda, menolak permintaan menyetir mobil, menyampaikan ajakan mengunjungi Ramayana, menolak ajakan mengunjungi Ramayana, menyatakan dukungan kepada idola Moto GP (Valentino Rossi), menyampaikan ajakan menghadiri pengajian rutin, tidak bisa memenuhi ajakan menghadiri pengajian rutin, menekankan bahwa pengertian alakadarnya sudah cukup jelas ( tidak perlu dipertanyakan lagi), memberitahu solusi karena ada warga sekitar yang ahli dalam hal dekorasi, memerintah atau menyuruh membersihkan ruang belajar, memesan gado-gado sesuai selera (menu tertentu), dan memberitahukan kondisi keuangannya sedang krisis sehingga tidak mampu memberi uang belanja yang layak kepada istri.

Untuk memperjelas uraian pembahasan di atas, di bawah ini penulis akan menyajikan data tentang proses analisis sepuluh peristiwa tutur bahasa Indonesia masyarakat Desa Megu Cilik Kabupaten Cirebon..

\section{Peristiwa tutur 1}

Kegiatan : Mempersiapkan acara khitanan masal

Tempat : Halaman depan rumah pemilik tenda.

Peserta : A. ( Pemuda / anggota panitia khitanan masal, usia \pm 30 tahun )

B. ( Pak Haji / pemilik usaha penyewaan tenda, usia \pm 50 tahun ) 
A : Assalammualaikum

B : Waalaikumussalam, eh ada apa ya, Dik Salim ?

A : Anu Pak Haji. Tadi malam panitia khitanan massal kan rapat. Kesimpulannya, semua biaya penyelenggaraan khitanan masal sudah tertangani, kecuali biaya sewa tenda, Pak Haji.. Menurut Pak Haji bagaimana?

B : Ooh, kalau gitu silakan ambil seperlunya, tapi nanti cepat dikembalikan, yah !

A : Siap Pak haji ! Terima kasih banyak.

B : Kendaraannya?

A : Jalan kaki saja, dekat ini Pak Haji,

Peristiwa tutur 1 di atas mengandung unsur inferensi. Unsur inferensi itu terdapat pada tuturan kesimpulannya, semua biaya penyelenggaraan khitanan masal sudah tertangani, kecuali biaya sewa tenda, Pak Haji.. Menurut Pak Haji bagaimana ? Dalam memahami makna yang secara tersurat (harfiah) tidak terdapat pada tuturan tersebut, pesapa (pendengar) menggunakan prinsip analogi penafsiran umum (penggunaan akal berdasarkan pengetahuan atau pengalaman masyarakat luas yang bersifat universal atau pengetahuan umum). Adapun makna inferensi yang terkandung dalam tuturan tersebut yaitu meminta bantuan pinjaman tenda.

\section{Peristiwa tutur 2}

Kegiatan : Mengantar pengantin

Tempat : Halaman depan rumah pengantin pria..

Peserta : A. (Keluarga pengantin pria / laki-laki berusia \pm 55 th)

B. (Anggota rombongan / laki-laki berusia \pm 45 th)

C. (Anggota rombongan / pemuda berusia \pm 30 th)

A : Mobilnya kurang satu (A berbicara di depan B dan C)

B : Pakai mobil saya saja. Tinggal cari sopirnya. Soalnya kaki saya sedang sakit.

A : Leh, kamu aja yang nyetir. (A berbicara kepada C)

C : Saya tidak bawa kaca mata, oom!

A : Lho, terus bagaimana?

C : Tuh, di mobil empat ada Karim. (sambil menunjuk mobil nomor empat)

A : Dia mau nggak yah ?

C : Paksa saja, oom!

Peristiwa tutur 2 di atas mengandung unsur inferensi. Unsur inferensi itu terdapat pada tuturan Saya tidak bawa kaca mata, oom! Dalam memahami makna yang secara tersurat (harfiah) tidak terdapat pada tuturan tersebut, pesapa (pendengar) menggunakan prinsip analogi penafsiran lokal (penggunaan akal berdasarkan pengetahuan atau pengalaman kelompok individu atau anggota masyarakat tertentu). Adapun makna inferensi yang terkandung dalam tuturan tersebut yaitu menolak permintaan menyetir mobil.

\section{Peristiwa tutur 3}

Kegiatan : Duduk-duduk santai

Tempat : Pinggir ( samping) lapangan bola.

Peserta : A. (Remaja putra berusia \pm 18 tahun)

B. (Remaja putra berusia \pm 18 tahun)

C. (Remaja putra berusia \pm 18 tahun) 
A : Halloo... Ramayana sedang banjir diskon, Coy ! (A yang baru datang ke lokasi dan menyapa B dan C)

B : Sekarang tanggal tua, Bro !

A : Yang penting kita hadir, Coy !

C : Dari pada makan angin, lebih baik makan Ketoprak di sini, Bro !

Peristiwa tutur 3 di atas mengandung unsur inferensi. Unsur inferensi itu terdapat pada tuturan Halloo... Ramayana sedang banjir diskon, Coy! dan tuturan Sekarang tanggal tua , Bro! Dalam memahami makna yang secara tersurat (harfiah) tidak terdapat pada dua tuturan tersebut, pesapa (pendengar) menggunakan prinsip analogi penafsiran umum. Adapun makna inferensi yang terkandung dalam tuturan pertama yaitu menyampaikan ajakan mengunjungi Ramayana sedangkan makna inferensi yang terkandung dalam tuturan kedua yaitu menolak ajakan mengunjungi Ramayana.

\section{Peristiwa tutur 4}

Kegiatan : Istirahat siang

Tempat : Warung baso

Peserta : A. (Remaja putra berusia \pm 18 tahun)

B. (Remaja putra berusia \pm 18 tahun)
A : Nanti malam ada Moto GP Qatar, ya,
B : Iya. Kamu pegang siapa?
A : Saya sih tetap The Doctor.
B : Sekarang sudah waktunya regenerasi, lho!
A : Iya sih. Tapi susah lho pindah haluan tuh.
B : Nekad, ya.

Peristiwa tutur 4 di atas mengandung unsur inferensi. Unsur inferensi itu terdapat pada tuturan Saya sih tetap The Doctor. Dalam memahami makna yang secara tersurat (harfiah) tidak terdapat pada tuturan tersebut, pesapa (pendengar) menggunakan prinsip analogi penafsiran umum. Adapun makna inferensi yang terkandung dalam tuturan tersebut yaitu menyatakan dukungan kepada idolanya yaitu Valentino Rossi.

\section{Peristiwa tutur 5}

Kegiatan : Perbincangan usai menunaikan sholat

Tempat : Halaman masjid

Peserta : A. (Seorang Ibu berusia \pm 35 tahun)

B. (Seorang Ibu berusia \pm 35 tahun)

A : Bu, jangan lupa besok ada jadwal pengajian rutin, lho !

B : Saya ada acara keluarga. Banyak tamu dari luar kota, Bu.

A : Memang waktunya bentrok ?

B : Takutnya seharian penuh, Bu.

Peristiwa tutur 5 di atas mengandung unsur inferensi. Unsur inferensi itu terdapat pada tuturan Bu, jangan lupa besok ada jadwal pengajian rutin, lho dan tuturan Saya ada acara 
keluarga. Dalam memahami makna yang secara tersurat (harfiah) tidak terdapat pada dua tuturan tersebut, pesapa (pendengar) menggunakan prinsip analogi penafsiran umum. Adapun makna inferensi yang terkandung dalam tuturan pertama yaitu menyampaikan ajakan menghadiri pengajian rutin, sedangkan makna inferensi yang terkandung dalam tuturan kedua yaitu tidak bisa memenuhi ajakan menghadiri pengajian rutin.

\section{Peristiwa tutur 6}

Kegiatan : Acara malam minggu

Tempat : Lapangan bola

Peserta : A. (Remaja putra berusia \pm 18 tahun)

B. (Remaja putra berusia \pm 18 tahun)
A : Teman-teman, acara kita kali ini amat sederhana, menunya juga alakadarnya.
B : Maksudnya?
A : Alakadarnya, ya alakadarnya.
B : Oke, oke.

Peristiwa tutur 6 di atas mengandung unsur inferensi. Unsur inferensi itu terdapat pada tuturan Alakadarnya, ya alakadarnya. Dalam memahami makna yang secara tersurat (harfiah) tidak terdapat pada tuturan tersebut, pesapa (pendengar) menggunakan prinsip analogi penafsiran umum. Adapun makna inferensi yang terkandung dalam tuturan tersebut yaitu menekankan pengertian alakadarnya sudah cukup jelas dan tidak perlu dipertanyakan lagi.

\section{Peristiwa tutur 7}

Kegiatan : Mempersiapkan perayaan ulang tahun

Tempat : Serambi rumah

Peserta : A. (Seorang pria berusia \pm 38 tahun)

B. (Seorang pria berusia \pm 35 tahun)

B : Assalammualaikum.

A : Walaikummussalam, silakan duduk, Pak.

B : Ngomong-ngomong, ada perlu apa ya Pak.

A : Minggu depan anak saya mau merayakan ulang tahun. Ia ingin mengundang semua teman sekolahnya. Konsumsi sih nggak masalah, tapi masalah dekorasi bikin pusing.

B : Gak usah bingung, kita kan punya Junaedi. Yang penting semua bahannya disediakan. Nanti saya yang akan menghubunginya.

A : Ya sudah, kalau begitu sih. Saya terima jadi, ya!

Peristiwa tutur 7 di atas mengandung unsur inferensi. Unsur inferensi itu terdapat pada tuturan kita kan punya Junaedi. Dalam memahami makna yang secara tersurat (harfiah) tidak terdapat pada tuturan tersebut, pesapa (pendengar) menggunakan prinsip analogi penafsiran lokal. Adapun makna inferensinya yaitu memberi tahu solusi karena ada warga sekitar yang ahli dalan hal dekorasi.. 


\section{Peristiwa tutur 8}

Kegiatan : Menunggu pembagian raport

Tempat : Ruang belajar madrasah diniyah.

Peserta : A. (Ibu guru berusia \pm 28 tahun )

B. ( Siswa madrasah berusia \pm 9 tahun)

C. ( Siswa madrasah berusia \pm 9 tahun)

D. ( Siswa madrasah berusia \pm 9 tahun)

A : Apakah di sini tidak ada sapu, ya? (Kalimat ini diucapkan ketika A melihat B, $\mathrm{C}$, dan $\mathrm{D}$ sedang bermain petak umpet dalam ruang belajar atau kelas yang berantakan dan banyak sampah )

$\mathrm{B}$ : Yang piket Yanto, Bu. (B menunjuk C)

A : Sudah ! Sekarang kalian tidak usah saling tunjuk.

B, C, D : Iya, Bu.

B : Huh, gara-gara kamu! (B menunjuk C)

A : Sudah! Tidak usah bertengkar!

Peristiwa tutur 8 di atas mengandung unsur inferensi. Unsur inferensi itu terdapat pada tuturan Apakah di sini tidak ada sapu, ya? Dalam memahami makna yang secara tersurat (harfiah) tidak terdapat pada tuturan tersebut, pesapa (pendengar) menggunakan prinsip analogi penafsiran umum. Adapun makna inferensi yang terkandung dalam tuturan tersebut yaitu menyuruh atau memerintah membersihkan ruangan belajar.

\section{Peristiwa tutur 9}

Kegiatan : Memesan (membeli) gado-gado

Tempat : Warung gado-gado

Peserta : A. (Pemuda berusia \pm 30 tahun)

B. (Seorang ibu berusia \pm 35 tahun)

B : Yu gado-gadonya satu, ijoan ya.

A : Tapi timunnya habis, Mas.

B : Nggak apa-apa. Berapa lagi ya?

A : Habis ini, dua lagi.

B : Nanti tolong antar ke kantor saja, ya.

A : Ya, Mas.

Peristiwa tutur 9 di atas mengandung unsur inferensi. Unsur inferensi itu terdapat pada tuturan : Yu gado-gadonya satu, ijoan ya. Dalam memahami makna yang secara tersurat (harfiah) tidak terdapat pada tuturan tersebut, pesapa (pendengar) menggunakan prinsip analogi penafsiran lokal (penggunaan akal berdasarkan pengetahuan atau pengalaman sekelompok individu atau sekelompok anggota masyarakat tertentu). Adapun makna inferensi yang terkandung dalam tuturan tersebut yaitu memesan atau membeli gado-gado sesuai selera atau menu tertentu yang mungkin hanya diketahui oleh pesapa dan penyapa. 


\section{Peristiwa tutur 10}

$\begin{array}{ll}\text { Kegiatan } & : \text { Menunggu penumpang becak } \\ \text { Tempat } & : \text { Pangkalan becak } \\ \text { Peserta } & \text { A. (Tukang becak laki-laki, berusia } \pm 30 \text { tahun) } \\ & \text { B. (Tukang becak laki-laki, berusia } \pm 30 \text { tahun) }\end{array}$
A : Tadi malam istriku marah-marah nggak jelas.
B : Emangnya kenapa?
A : Ya ... nggak tahu
B : Ya nggak mungkin lah, kalau nggak ada sebabnya.
A : Kamu kan tahu. Tiga hari ini hujan terus. Otomatis dompetku merana.
B : Oh itu toh masalahnya.
A : Ya .... itu masalahnya, duit duit.

Peristiwa tutur 10 di atas mengandung unsur inferensi. Unsur inferensi itu terdapat pada tuturan Otomatis dompetku merana. Dalam memahami makna yang secara tersurat (harfiah) tidak terdapat pada tuturan tersebut, pesapa (pendengar) menggunakan prinsip analogi penafsiran umum (penggunaan akal berdasarkan pengetahuan dan pengalaman masyarakat luas atau pengetahuan umum yang bersifat universal). Adapun makna inferensi yang terkandung dalam tuturan tersebut yaitu memberitahukan kondisi keuangannya sedang krisis sehingga tidak mampu memberi uang belanja yang layak kepada istri.

\section{Simpulan}

Bertitik tolak dari rumusan masalah dan pembahasan hasil penelitian ini, penulis dapat mengambil simpulan seperti di bawah ini.

1. Dalam komunikasi berbahasa atau kegiatan berbahasa sehari-hari, masyarakat Desa Megu Cilik Kabupaten Cirebon di samping menggunakan bahasa ibu (bahasa Jawa Cirebon), juga menggunakan bahasa Indonesia.

2. Hasil analisis terhadap sepuluh peristiwa tutur bahasa Indonesia masyarakat Desa Megu Cilik Kabupaten Cirebon menunjukkan bahwa semua atau kesepuluh peristiwa tutur tersebut mengandung unsur inferensi. Adapun rincian bentuk dan maknanya adalah sebagai berikut :

a. Dari sepuluh peristiwa tutur bahasa Indonesia yang diamati (dianalisis), terdapat tujuh peristiwa tutur yang mengandung bentuk prinsip analogi penafsiran umum, yaitu peristiwa tutur $1,3,4,5,6,8$, dan 10 . Sedangkan sisanya yaitu tiga peristiwa tutur (peristiwa tutur 2, 7, dan 9) mengandung bentuk prinsip analogi penafsiran lokal.

b. Makna inferensi yang terdapat pada sepuluh peristiwa tutur bahasa Indonesia yang diamati (dianalisis) meliputi :

1) Meminta bantuan pinjaman tenda ;

2) Menolak permintaan menyetir mobil.;

3) Menyampaikan ajakan mengunjungi Ramayana ;

4) Menolak ajakan mengunjungi Ramayana ;

5) Menyatakan dukungan kepada idola Moto GP (Valentino Rossi) ;

6) Menyampaikan ajakan menghadiri pengajian rutin ; 
7) Tidak bisa memenuhi ajakan menghadiri pengajian rutin ;

8) Menekankan bahwa pengertian alakadarnya sudah cukup jelas dan tidak perlu dipertanyakan lagi.

9) Memberi tahu solusi karena ada warga sekitar (orang dekat) yang ahli dalam hal dekorasi ;

10) Memerintah atau menyuruh membersihkan ruang belajar ;

11) Memesan gado-gado sesuai selera (menu tertentu);

12) Memberitahukan kondisi keuangannya sedang krisis sehingga tidak mampu memberi uang belanja yang layak kepada istri.

\section{Daftar Pustaka}

Alwasilah, A. C. (1985). Sosioligi Bahasa. Bandung : Angkasa.

Alwi, H, dkk. (2003). Tata Bahasa Baku Bahasa Indonesia. Jakarta : Balai Pustaka.

Bell, R. T. (1976). Sociolinguistis: Goals, Approaches, and Problems. London: Batsford Ltd.

Chaer, A. (1994). Linguistik Umum. Jakarta : Rineka Cipta.

Chaer, A. dan Agustina, L. (2004). Sosiolinguistik. Jakarta: Rineka Cipta.

Cherry, C. (1957). On Human Communication. New York : MIT and Jhon Woley And Sons.

Djajasudarma, T. F. (1989). Semantik II ( Pemahaman Ilmu Makna ). Bandung: Fak. Sastra Universitas Padjajaran. ( 1993 : PT Eresvo).

(2016). Wacana. Pemahaman dan Hubungan Antarunsur. Bandung: Refika Aditama.

Gazdar. G. (1979). Pragmatics: Implicature, Presupposition, and Logical Form. New York: Academic Prees.

Kridalaksana, H. (1982). Fungsi Bahasa dan Sikap Bahasa. Ende Flores : Nusa Indah.

Levinson, S. C. (1983). Pragmatics. Cambridge ; Cambridge University Prees.

Samsuri. (1988). Analisis Wacana. Malang: Proyek Peningkatan/ Pengembangan Perguruan Tinggi Malang. Swales John M.

Sugiyono. (2013). Metode Penelitian Kuantitatif, Kualitatif, dan R\&D. Bandung : Alphabeta.

Sumarsono. (2013). Sosiolinguistik. Yogyakarta : SABDA.

Suwito. (1983). Sosiolinguistik: Teori dan Problema. Surakarta : Kenary Offsett.

Yule, G. (2006). Pragmatik. Yogyakarta : Pustaka Pelajar.

(2015). Kajian Bahasa. Yogyakarta : Pustaka Pelajar. 